\title{
Demographic Variability of Urinary Tract Stones in Saudi Arabia
}

\section{AL-Nasser KA*, Neel AF, Alyami FA, Al-Barraq KM, Alsheheli MM, Alomar MA, Althunayan AM, Binsaleh SA and Almannie RM}

Department of Surgery, King Saud University, Saudi Arabia

*Corresponding author: Khalid Abdulrahman AL Nasser, College of Medicine, King Saud University Medical City, Department of Surgery-Division of Urology, King Saud University, Fax: +96614679493, Tel: +966554648000; Email: Khalid55alnasser@gmail.com

\section{Research Article \\ Volume 5 Issue 2}

Received Date: August 11, 2020

Published Date: August 27, 2020

DOI: 10.23880/oajun-16000182

\section{Abstract}

Objectives: Urinary tract stones are a highly prevalent problem affecting public health worldwide. Studying demographic variability in urolithiasis across different geographical areas in terms of prevalence, age, sex, stone composition, climate, and comorbidities can aid in differentiating between varieties of stone types and identifying high-risk populations. We conducted this study to identify correlations and demonstrate the demographic variability in urinary tract stone cases in Saudi Arabia. Methods: We retrospectively reviewed the data of all patients who underwent stone analysis in our institution between May 2015 and June 2017. We used Fourier transform infrared (FT-IR) spectroscopy for stone analysis to analyze the chemical composition of each stone. We recorded the different seasons when the stones were initially analyzed and the demographics of our patients, including age, sex, general comorbidities such as hypertension, diabetes, and other patient-specific comorbidities, and stone type.

Results: We analyzed the data using the statistical data analysis software IBM SPSS Statistics for Windows, Version 25.0. (Armonk, NY: IBM Corp) to assess a sample of 433 patients with urolithiasis who underwent FT-IR in our institution. We divided the ages of the patients into seven distinct age groups $(0-14,15-24,25-34,35-44,45-54,55-64,+65)$ to easily define and compare the incidence of stones within each age group and between sexes. We divided the year into hot and cold seasons according to the annual climate in Saudi Arabia. We also defined patients' coexisting comorbidities in our results.

Conclusion: We found that the incidence of some types of urinary tract stones could be predicted by the presence of chronic illnesses in the middle-aged population in Saudi Arabia.

Keywords: Urinary Tract Stones; Urolithiasis; Demographic

\section{Introduction}

Urinary tract stones are a highly prevalent problem affecting public health worldwide [1]. The prevalence of urolithiasis worldwide ranges between $4 \%$ and $20 \%$ in welldeveloped countries [2]. In Saudi Arabia, the prevalence of urolithiasis is between $11.2 \%$ and $48.8 \%$ [3]. Most of these stones are calcium oxalate and calcium phosphate stones, accounting for more than $80 \%$ of the total of all types of urinary tract stones. Other types of stones, including uric acid, cysteine, and struvite stones, account for most of the remaining $20 \%$ of stones [4]. The incidence and prevalence of urolithiasis vary among different geographical locations and races and between sexes [5]. The lifetime incidence of urolithiasis reaches up to $25 \%$ in Middle Eastern countries [6].

The pathophysiology of urolithiasis is not fully understood; many factors, such as metabolic, genetic, and environmental factors, contribute to the formation of stones 


\section{Open Access Journal of Urology \& Nephrology}

$[7,8]$. The demographics of those affected by urinary system stones vary across different geographical areas in terms of prevalence, age, sex, stone composition, and stone location. Additionally, other variable factors have been investigated in the literature, such as race, diet and changing socioeconomic conditions, which may affect the epidemiological distribution in terms of stone composition [2]. The incidence of stones among populations in geographical areas with hot climates was much higher than that among populations in moderate climate areas [9]. The presence of other risk factors, such as obesity, diabetes mellitus (DM), hypertension (HTN), metabolic syndrome, decreased fluid intake, increased perspiration and dietary habits, may promote crystallization and the formation of urinary tract stones $[10,11]$.

This study aims to correlate and demonstrate the demographic variability of urinary tract stones in Saudi Arabia. This aim was addressed by analyzing data from patients who underwent urinary tract stone analysis via Fourier transform infrared spectroscopy (FT-IR).

\section{Material and Methods}

A retrospective study including 433 patients who underwent stone analysis via FT-IR in our institution over a period of three years - from May 2015 to June 2017was conducted. The analyzed stones were either passed spontaneously, passed after fragmentation by shockwave lithotripsy or extracted surgically by ureteroscopy or percutaneous nephrolithotomy.

This study was supported by a grant from the College of Medicine Research Center, Deanship of Scientific Research at King Saud University, after obtaining Institutional Review Board (IRB) approval. We subsequently obtained the data from the special biochemistry laboratory at King Khalid University Hospital (KKUH). The privacy of the patients was maintained throughout the entire research process.

Extracted data included the demographics of the patients, including age, sex, general comorbidities such as HTN, DM, dyslipidemia, and other patient-specific comorbidities, and stone types. Furthermore, we divided the year into hot and cold seasons based on the climate in Saudi Arabia and classified the data according to when the stones were initially analyzed. The hot season occurs from May to September, while the cold season starts in October and lasts until the end of April the following year.

Once the data were collected, a researcher verified the completeness of the information. It was then coded, loaded, and analyzed by Statistical Package for Social Science (SPSS ${ }^{\circledR} \square$ ) program version 25.0. (Armonk, NY: IBM Corp); a p-value less than 0.05 was considered significant. Descriptive statistics were used to compute means, variances, and standard deviations.

\section{Results}

We analyzed our data using the statistical data analysis software IBM SPSS Statistics for Windows, Version 25.0. (Armonk, NY: IBM Corp) to assess a sample of 433 patients with urolithiasis who underwent FT-IR in our institution. In our study, Saudis accounted for 316 of the total sample, while 117 of the sample were non-Saudis. Most of the studied samples were from males $(n=316,73 \%$; females, $n=117$, $27 \%$ ). The male-to-female ratio was estimated to be $2.7: 1$ (Table 1). We divided the ages of the patients into seven distinct age groups $(0-14,15-24,25-34,35-44,45-54,55-64$, $+65)$ to easily define and compare the incidence of stones within each age group.

\begin{tabular}{|c|c|c|}
\hline & Total number & Percentage \\
\hline Stones & 433 & 100 \\
\hline Male & 316 & 73 \\
\hline Female & 117 & 27 \\
\hline Male/female ratio & \multicolumn{2}{|c|}{$2.7: 1$} \\
\hline Age (years) average & \multicolumn{2}{|c|}{43.47} \\
\hline Saudi & 384 & 88.7 \\
\hline Non-Saudi & 49 & 11.3 \\
\hline Hot season & 217 & 50.1 \\
\hline Cold season & 216 & 49.9 \\
\hline DM & 101 & 23.3 \\
\hline HTN & 88 & 20.3 \\
\hline
\end{tabular}

Table 1: Demographics of the study population.

Our study included 23 cases of stones in the 0-14 age group; most of these stones were carbonate apatite $(n=9$, $39.1 \%)$, calcium oxalate $(\mathrm{n}=6,26 \%)$, and cystine stones $(\mathrm{n}=4$, $17.3 \%$ of all stones within the same age group). We had 21 cases of stones in the 15-24 age group; most of these stones were carbonate apatite $(n=9,42.8 \%)$, calcium oxalate $(n=8$, $38 \%)$, and ammonium stones $(\mathrm{n}=2,9.5 \%)$. There were 87 cases of stones in the 25-34 age group; most of these stones were calcium oxalate $(\mathrm{n}=45,51.7 \%)$, carbonate apatite $(\mathrm{n}=24,27.5 \%)$, and cysteine stones $(\mathrm{n}=11,12.6 \%)$. There were 99 cases of stones in the 35-44 age group; most of these stones were calcium oxalate $(n=57,57.5 \%)$, carbonate apatite $(n=35,35.3 \%)$, and uric acid stones $(n=6,6 \%)$. There were 84 cases of stones in the 45-54 age group; most of these stones were calcium oxalate $(n=56,66.6 \%)$, carbonate apatite $(n=15,17.8 \%)$, and uric acid stones $(n=12,14.2 \%)$. There were 76 cases of stones in the 55-64 age group; most of these stones were calcium oxalate $(n=41,53.9 \%)$, carbonate 


\section{Open Access Journal of Urology \& Nephrology}

apatite $(n=30,39.4 \%)$, and uric acid stones $(n=3,3.9 \%)$. Finally, there were 43 cases in the +65 age group; most of these stones were carbonate apatite $(n=22,51.1 \%)$, calcium oxalate $(n=14,32.5 \%)$, and uric acid stones $(n=6,13.9 \%)$. Calcium oxalate stones accounted for most of the studied stones $(\mathrm{n}=227,52.4 \%)$, followed by carbonate apatite stones $(n=144,33.2 \%)$; other types were rare, constituting a total of $62(14.3 \%)$. Furthermore, we calculated the $p$-value for age in relation to stone type, which was highly significant at $<$ 0.0005 (Table 2).

\begin{tabular}{|c|c|c|c|c|c|c|c|c|c|}
\hline \multirow{2}{*}{\multicolumn{2}{|c|}{ P-value $<0.0005$}} & \multicolumn{7}{|c|}{ Age } & \multirow{3}{*}{$\begin{array}{c}\text { Total } \\
1\end{array}$} \\
\hline & & \multirow{2}{*}{$\frac{\mathbf{0 - 1 4}}{0}$} & \multirow{2}{*}{$\frac{15-24}{0}$} & \multirow{2}{*}{$\frac{25-34}{1}$} & \multirow{2}{*}{$\frac{35-44}{0}$} & \multirow{2}{*}{$\frac{45-54}{0}$} & \multirow{2}{*}{$\begin{array}{c}\mathbf{5 5 - 6 4} \\
0\end{array}$} & \multirow{2}{*}{$\frac{65+}{0}$} & \\
\hline Ammonium & Count & & & & & & & & \\
\hline Urate & $\%$ & $0.00 \%$ & $0.00 \%$ & $100.00 \%$ & $0.00 \%$ & $0.00 \%$ & $0.00 \%$ & $0.00 \%$ & $100.00 \%$ \\
\hline \multirow{2}{*}{$\begin{array}{l}\text { Ammonium } \\
\text { Hydrogen Urate }\end{array}$} & Count & 0 & 0 & 1 & 1 & 0 & 0 & 0 & 2 \\
\hline & $\%$ & $0.00 \%$ & $0.00 \%$ & $50.00 \%$ & $50.00 \%$ & $0.00 \%$ & $0.00 \%$ & $0.00 \%$ & $100.00 \%$ \\
\hline \multirow{2}{*}{$\begin{array}{l}\text { Ammonium } \\
\text { Magnesium } \\
\text { Phosphate }\end{array}$} & Count & 3 & 2 & 1 & 0 & 0 & 1 & 1 & 8 \\
\hline & $\%$ & $37.50 \%$ & $25.00 \%$ & $12.50 \%$ & $0.00 \%$ & $0.00 \%$ & $12.50 \%$ & $12.50 \%$ & $100.00 \%$ \\
\hline \multirow{2}{*}{$\begin{array}{l}\text { Ammonium } \\
\text { Magnesium } \\
\text { Hexahydrate }\end{array}$} & Count & 1 & 0 & 0 & 0 & 0 & 0 & 0 & 1 \\
\hline & $\%$ & $100.00 \%$ & $0.00 \%$ & $0.00 \%$ & $0.00 \%$ & $0.00 \%$ & $0.00 \%$ & $0.00 \%$ & $100.00 \%$ \\
\hline \multirow{2}{*}{ Calcium Oxalate } & Count & 6 & 8 & 45 & 57 & 56 & 41 & 14 & 227 \\
\hline & $\%$ & $2.60 \%$ & $3.50 \%$ & $19.80 \%$ & $25.10 \%$ & $24.70 \%$ & $18.10 \%$ & $6.20 \%$ & $100.00 \%$ \\
\hline \multirow{2}{*}{$\begin{array}{c}\text { Carbonate } \\
\text { Apatite }\end{array}$} & Count & 9 & 9 & 24 & 35 & 15 & 30 & 22 & 144 \\
\hline & $\%$ & $6.20 \%$ & $6.20 \%$ & $16.70 \%$ & $24.30 \%$ & $10.40 \%$ & $20.80 \%$ & $15.30 \%$ & $100.00 \%$ \\
\hline \multirow{2}{*}{ Cystine } & Count & 4 & 2 & 11 & 0 & 0 & 1 & 0 & 18 \\
\hline & $\%$ & $22.20 \%$ & $11.10 \%$ & $61.10 \%$ & $0.00 \%$ & $0.00 \%$ & $5.60 \%$ & $0.00 \%$ & $100.00 \%$ \\
\hline \multirow{2}{*}{$\begin{array}{l}\text { Monohydrogen } \\
\text { Phosphate }\end{array}$} & Count & 0 & 0 & 0 & 0 & 1 & 0 & 0 & 1 \\
\hline & $\%$ & $0.00 \%$ & $0.00 \%$ & $0.00 \%$ & $0.00 \%$ & $100.00 \%$ & $0.00 \%$ & $0.00 \%$ & $100.00 \%$ \\
\hline \multirow{2}{*}{ Uric Acid } & Count & 0 & 0 & 1 & 0 & 0 & 0 & 0 & 1 \\
\hline & $\%$ & $0.00 \%$ & $0.00 \%$ & $100.00 \%$ & $0.00 \%$ & $0.00 \%$ & $0.00 \%$ & $0.00 \%$ & $100.00 \%$ \\
\hline \multirow{2}{*}{$\begin{array}{l}\text { Uric Acid } \\
\text { Dihydrate }\end{array}$} & Count & 0 & 0 & 3 & 6 & 12 & 3 & 6 & 30 \\
\hline & $\%$ & $0.00 \%$ & $0.00 \%$ & $10.00 \%$ & $20.00 \%$ & $40.00 \%$ & $10.00 \%$ & $20.00 \%$ & $100.00 \%$ \\
\hline \multirow{2}{*}{ Total } & Count & 23 & 21 & 87 & 99 & 84 & 76 & 43 & 433 \\
\hline & $\%$ & $5.30 \%$ & $4.80 \%$ & $20.10 \%$ & $22.90 \%$ & $19.40 \%$ & $17.60 \%$ & $9.90 \%$ & $100.00 \%$ \\
\hline
\end{tabular}

Table 2: The relationship between age and stone type, with p-values.

The highest incidence of stones in both sexes occurred in the 35-44 age group ( $\mathrm{n}=99,22.9 \%)$, followed by the $25-34$ age group $(n=87,20.1 \%)$. The lowest incidence of stones in both sex occurred in the 15-24 age group $(n=21,4.8 \%)$ (Table 3). Our study showed an almost identical number of cases in the hot and cold seasons. In the hot season, there were 217 cases, and in the cold season, there were 216 cases [Table 1]. Regarding comorbidities within our sample, DM was prevalent in 101 patients; most of them had calcium oxalate stones $(n=49,49 \%)$, carbonate apatite stones $(n=33,33 \%)$, and uric acid stones $(n=15,15 \%)$. The rest of the stones were unremarkable. The p-value for DM was calculated, and its relation with different types of stones was significant at 0.041 (Table 4). HTN was present in 88 patients; most of them had calcium oxalate $(n=42,48 \%)$, carbonate apatite $(\mathrm{n}=32,36 \%)$, and uric acid stones $(\mathrm{n}=12,14 \%)$. The other types of stones were unremarkable. The p-value for HTN and its relation with different types of stones was significant at 0.04 (Table 5). 


\section{Open Access Journal of Urology \& Nephrology}

\begin{tabular}{|c|c|c|c|c|}
\hline \multicolumn{5}{|c|}{ Age and sex with number of cases } \\
\hline & & \multicolumn{2}{|c|}{ Sex } & \multirow{2}{*}{ Total } \\
\hline & & Female & Male & \\
\hline \multirow{2}{*}{$0-14$} & Count & 9 & 14 & 23 \\
\hline & \% within Sex & $7.70 \%$ & $4.40 \%$ & $5.30 \%$ \\
\hline \multirow{2}{*}{$15-24$} & Count & 7 & 14 & 21 \\
\hline & \% within Sex & $6.00 \%$ & $4.40 \%$ & $4.80 \%$ \\
\hline \multirow{2}{*}{$35-34$} & Count & 24 & 63 & 87 \\
\hline & \% within Sex & $20.50 \%$ & $19.90 \%$ & $20.10 \%$ \\
\hline \multirow{2}{*}{$35-44$} & Count & 27 & 72 & 99 \\
\hline & $\%$ within Sex & $23.10 \%$ & $22.80 \%$ & $22.90 \%$ \\
\hline \multirow{2}{*}{$45-54$} & Count & 18 & 66 & 84 \\
\hline & \% within Sex & $15.40 \%$ & $20.90 \%$ & $19.40 \%$ \\
\hline \multirow{2}{*}{$55-64$} & Count & 25 & 51 & 76 \\
\hline & $\%$ within Sex & $21.40 \%$ & $16.10 \%$ & $17.60 \%$ \\
\hline \multirow{2}{*}{65} & Count & 7 & 36 & 43 \\
\hline & \% within Sex & $6.00 \%$ & $11.40 \%$ & $9.90 \%$ \\
\hline \multirow{2}{*}{ Total } & Count & 117 & 316 & 433 \\
\hline & \% within Sex & $100.00 \%$ & $100.00 \%$ & $100.00 \%$ \\
\hline
\end{tabular}

Table 3: Age and sex with percentages of cases.

\begin{tabular}{|c|c|c|c|c|}
\hline \multicolumn{5}{|c|}{ P-value $=0.041$} \\
\hline & & & & \\
\hline & & NO & YES & Total \\
\hline \multirow{2}{*}{ Ammonium Dihydrogen Urate } & Count & 1 & 0 & 1 \\
\hline & $\%$ & $100.00 \%$ & $0.00 \%$ & $100.00 \%$ \\
\hline \multirow{2}{*}{ Ammonium Hydrogen Urate } & Count & 1 & 1 & 2 \\
\hline & $\%$ & $50.00 \%$ & $50.00 \%$ & $100.00 \%$ \\
\hline \multirow{2}{*}{ Ammonium Magnesium Phosphate } & Count & 6 & 2 & 8 \\
\hline & $\%$ & $75.00 \%$ & $25.00 \%$ & $100.00 \%$ \\
\hline \multirow{2}{*}{$\begin{array}{c}\text { Ammonium Magnesium } \\
\text { Hexahydrate }\end{array}$} & Count & 1 & 0 & 1 \\
\hline & $\%$ & $100.00 \%$ & $0.00 \%$ & $100.00 \%$ \\
\hline \multirow{2}{*}{ Calcium Oxalate } & Count & 178 & 49 & 227 \\
\hline & $\%$ & $78.40 \%$ & $21.60 \%$ & $100.00 \%$ \\
\hline \multirow{2}{*}{ Carbonate Apatite } & Count & 111 & 33 & 144 \\
\hline & $\%$ & $77.10 \%$ & $22.90 \%$ & $100.00 \%$ \\
\hline \multirow{2}{*}{ Cystine } & Count & 17 & 1 & 18 \\
\hline & $\%$ & $94.40 \%$ & $5.60 \%$ & $100.00 \%$ \\
\hline \multirow{2}{*}{ Monohydrogen Phosphate } & Count & 1 & 0 & 1 \\
\hline & $\%$ & $100.00 \%$ & $0.00 \%$ & $100.00 \%$ \\
\hline \multirow{2}{*}{ Uric Acid } & Count & 1 & 0 & 1 \\
\hline & $\%$ & $100.00 \%$ & $0.00 \%$ & $100.00 \%$ \\
\hline \multirow{2}{*}{ Uric Acid Dihydrate } & Count & 15 & 15 & 30 \\
\hline & $\%$ & $50.00 \%$ & $50.00 \%$ & $100.00 \%$ \\
\hline \multirow{2}{*}{ Total } & Count & 332 & 101 & 433 \\
\hline & $\%$ & $76.70 \%$ & $23.30 \%$ & $100.00 \%$ \\
\hline
\end{tabular}

Table 4: The relationship between stone type and diabetes mellites, with p-values. 


\section{Open Access Journal of Urology \& Nephrology}

\begin{tabular}{|c|c|c|c|c|}
\hline \multicolumn{5}{|c|}{ P-value $=0.040$} \\
\hline \multirow{2}{*}{\multicolumn{2}{|c|}{ Stone Type }} & \multicolumn{2}{|c|}{ HTN } & \multirow{3}{*}{$\begin{array}{c}\text { Total } \\
1\end{array}$} \\
\hline & & NO & YES & \\
\hline \multirow{2}{*}{ Ammonium Dihydrogen Urate } & Count & 1 & 0 & \\
\hline & $\%$ & $100.00 \%$ & $0.00 \%$ & $100.00 \%$ \\
\hline \multirow{2}{*}{ Ammonium Hydrogen Urate } & Count & 2 & 0 & 2 \\
\hline & $\%$ & $100.00 \%$ & $0.00 \%$ & $100.00 \%$ \\
\hline \multirow{2}{*}{ Ammonium Magnesium Phosphate } & Count & 8 & 0 & 8 \\
\hline & $\%$ & $100.00 \%$ & $0.00 \%$ & $100.00 \%$ \\
\hline \multirow{2}{*}{ Ammonium Magnesium Hexahydrate } & Count & 1 & 0 & 1 \\
\hline & $\%$ & $100.00 \%$ & $0.00 \%$ & $100.00 \%$ \\
\hline \multirow{2}{*}{ Calcium Oxalate } & Count & 185 & 42 & 227 \\
\hline & $\%$ & $81.50 \%$ & $18.50 \%$ & $100.00 \%$ \\
\hline \multirow{2}{*}{ Carbonate Apatite } & Count & 112 & 32 & 144 \\
\hline & $\%$ & $77.80 \%$ & $22.20 \%$ & $100.00 \%$ \\
\hline \multirow{2}{*}{ Cystine } & Count & 17 & 1 & 18 \\
\hline & $\%$ & $94.40 \%$ & $5.60 \%$ & $100.00 \%$ \\
\hline \multirow{2}{*}{ Monohydrogen Phosphate } & Count & 0 & 1 & 1 \\
\hline & $\%$ & $0.00 \%$ & $100.00 \%$ & $100.00 \%$ \\
\hline \multirow{2}{*}{ Uric Acid } & Count & 1 & 0 & 1 \\
\hline & $\%$ & $100.00 \%$ & $0.00 \%$ & $100.00 \%$ \\
\hline \multirow{2}{*}{ Uric Acid Dihydrate } & Count & 18 & 12 & 30 \\
\hline & $\%$ & $60.00 \%$ & $40.00 \%$ & $100.00 \%$ \\
\hline \multirow{2}{*}{ Total } & Count & 345 & 88 & 433 \\
\hline & $\%$ & $79.70 \%$ & $20.30 \%$ & $100.00 \%$ \\
\hline
\end{tabular}

Table 5: The relationship between stone type and hypertension, with p-values.

\section{Discussion}

Urolithiasis is one of the most common health problems treated by urologists worldwide [12]. It has a significant impact on people's general wellbeing. It is associated with an increased risk of urinary tract infections, chronic kidney disease, hypertension, and myocardial infarction [13]. Additionally, there is a substantial cost associated with providing medical treatment to affected individuals. In a study analyzing claims from 25 large employers in the US, approximately one-third of employees treated for nephrolithiasis in 2000 missed work due to the condition, with an average work loss for the entire treated population of 19 hours per person. Considering those that received treatment, the incremental cost of nephrolithiasis was 3,494 US dollars per person in 2000 [14]. Studying the core elemental composition of stones and the factors contributing to their development may help us identify high-risk groups. This study's focus was correlations of age, sex, climate, and preexisting comorbidities with the formation of stones requiring treatment.

\section{Age and Sex}

We found that the incidence increased with age in our cohort. This is likely due to the increasing incidence of comorbidities such as DM, HTN, dyslipidemia, and obesity with age [15]. We also found that males had a higher incidence of urinary tract stones than females; the reason may be related to sex hormones [16]. A positive relationship exists between high plasma androgen concentrations and the incidence of kidney stones, which suggests a potential role of gonadal steroids in the pathogenic mechanism in male urolithiasis [17]. In our study, there was a significant correlation between age and stone type (p-values $<0.0005$ ). Generally, calcium oxalate stones were the most common type, followed by calcium apatite stones, which were more common in the polar extremes of age.

\section{Climate}

In our study, there was no significant difference between hot and cold seasons, unlike results reported in similar studies that found the incidence to be higher in the hot 


\section{Open Access Journal of Urology \& Nephrology}

seasons. A large Saudi epidemiological study published in 1997 found a strong correlation between urolithiasis and both temperature and atmospheric pressure, with p-values of $<0.0001$. Interestingly, they found no significant correlation between incidence and Ramadan fasting or the pilgrimage festival [18].

\section{Comorbidities}

Metabolic syndrome, characterized by multiple cardiometabolic alterations, is a multifactorial disorder leading to an increase in urinary acid secretion, thereby lowering urine $\mathrm{pH}$, leading to acid crystal deposition and stone formation [19]. Based on our data, we found that the coexistence of a chronic illnesses and obesity was highly associated with stone formation. Most of the stones that underwent FT-IR in our institution were from patients who had risk factors for urolithiasis. In our study, we used FT-IR in the analysis of stones, as FT-IR has been demonstrated to overcome many limitations associated with chemical analyses [20]. However, since this method has been newly implemented in our center ( $<3$ years), our sample size was too small to compare the results with those of similar studies in which the method had been used for a longer time.

In terms of stone type, among our diabetic and hypertensive study populations, calcium oxalate was the most common stone type, followed by calcium apatite stones. This follows a pattern similar to the stone distribution among different age groups, likely indicating a general observation that calcium oxalate and calcium apatite stones are the most common types of stones among the Saudi population regardless of different risk factors. Further large-sample studies are needed to validate such a claim.

\section{Conclusion}

Our study showed a correlation between aging and the incidence of urinary tract stones. It also showed an increased prevalence among the male population. In contrast, we did not find a correlation between stone incidence and changes in climate. While there was a clear correlation between patients with comorbidities developing urinary stones, a larger study sample size with a larger scope of concomitant illnesses is needed to further analyze this relationship.

\section{References}

1. Alkhunaizi AM (2016) Urinary stones in Eastern Saudi Arabia. Urol Ann 8(1): 6-9.

2. Trinchieri A (2008) Epidemiology of urolithiasis: an update. Clin Cases Miner Bone Metab 5(2): 101-106.

3. Baatiah NY, Alhazmi RB, Albathi FA, Albogami EG,
Mohammedkhalil AK, et al. (2020) Urolithiasis: prevalence, risk factors, and public awareness regarding dietary and lifestyle habits in Jeddah, Saudi Arabia in 2017. Urol Ann 12(1): 57-62.

4. Barnela SR, Soni SS, Saboo SS, Bhansali AS (2012) Medical management of renal stone. Indian J Endocrinol Metab 16(2): 236-239.

5. Turney BW, Appleby PN, Reynard JM, Noble JG, Key TJ, et al. (2014) Diet and risk of kidney stones in the Oxford cohort of the European prospective investigation into cancer and nutrition (EPIC). Eur J Epidemiol 29(5): 363369.

6. Khan SR, Pearle MS, Robertson WG, Gambaro G, Canales BK, Doizi S, Traxer O, Tiselius H-G (2017) Kidney stones. Nat Rev Dis Primers 2: 16008.

7. Lieske JC, Rule AD, Krambeck AE, Williams JC, Bergstralh EJ, et al. (2014) Stone composition as a function of age and sex. Clin J Am Soc Nephrol 9(12): 2141-2146.

8. Shadman A, Bastani B (2017) Kidney Calculi: pathophysiology and as a systemic disorder. Iran J Kidney Dis 11(3): 180-191.

9. Soucie JM, Thun MJ, Coates RJ, McClellan W, Austin H (1994) Demographic and geographic variability of kidney stones in the United States. Kidney Int 46(3): 893-899.

10. Gault MH, Chafe L (2000) Relationship of frequency, age, sex, stone weight and composition in 15,624 stones: comparison of resutls for 1980 to 1983 and 1995 to 1998. J Urol 164(2): 302-307.

11. Knoll T (2010) Epidemiology, pathogenesis, and pathophysiology of urolithiasis. Eur Urol Suppl 9(12): 802-806.

12. Romero V, Akpinar H, Assimos DG (2010) Kidney stones: a global picture of prevalence, incidence, and associated risk factors. Rev Urol 12(2-3): 86-96.

13. Hsiao CY, Chen TH, Lee YC, Hsiao MC, Hung PH, et al. (2019) Urolithiasis is a risk factor for uroseptic shock and acute kidney injury in patients with urinary tract infection. Front Med 6: 288.

14. Saigal CS, Joyce G, Timilsina AR (2005) Direct and indirect costs of nephrolithiasis in an employed population: opportunity for disease management?. Kidney Int 68(4): 1808-1814.

15. Bartoletti R, Cai T, Mondaini N, Melone F, Travaglini F, et al. (2007) Epidemiology and risk factors in urolithiasis. 


\section{Open Access Journal of Urology \& Nephrology}

Urol Int 79 (1): 3-7.

16. Kato Y, Yamaguchi S, Kakizaki H, Yachiku S (2005) Influence of estrus status on urinary chemical parameters related to urolithiasis. Urol Res 33(6): 476-480.

17. Naghii MR, Babaei M, Hedayati M (2014) Androgens involvement in the pathogenesis of renal stones formation. PLoS One 9(4): e93790.
18. Al-Hadramy MS (1997) Seasonal variations of urinary stone colic in Arabia. J Pak Med Assoc 47(11): 281-284.

19. Wong YV, Cook P, Somani BK (2015) The association of metabolic syndrome and urolithiasis. Int J Endocrinol 2015: 570674.

20. Khan AH, Imran S, Talati J, Jafri L (2018) Fourier transform infrared spectroscopy for analysis of kidney stones. Investig Clin Urol 59(1): 32-37. 